University of Wollongong

Research Online

Faculty of Social Sciences - Papers (Archive) Faculty of Arts, Social Sciences \& Humanities

$1-1-2018$

Why do I think my team is capable? A study of some antecedents of team members' personal collective efficacy beliefs

Seyyed B. Alavi

Sharif University of Technology, sbalavi@sharif.edu

John McCormick

University of Wollongong, johnmcc@uow.edu.au

Follow this and additional works at: https://ro.uow.edu.au/sspapers

Part of the Education Commons, and the Social and Behavioral Sciences Commons

Research Online is the open access institutional repository for the University of Wollongong. For further information contact the UOW Library: research-pubs@uow.edu.au 


\title{
Why do I think my team is capable? A study of some antecedents of team members' personal collective efficacy beliefs
}

\author{
Abstract \\ Few studies have been conducted about team members' individual beliefs of their team's collective \\ efficacy (personal collective efficacy). We argue that this individual belief is a motivational factor for \\ teamwork along with self-efficacy for teamwork. This study investigated relationships between personal \\ collective efficacy, self-efficacy for teamwork, collective orientations and perceptions of self in relation to \\ other team members. In addition, relationships between personal collective efficacy and team members' \\ perceptions of team activities namely evaluating and integrating were explored. Multilevel analysis was \\ employed in order to account for team level variation when testing individual level relationships. Eighty-six \\ university student teams were followed throughout a two-stage study. We found personal collective \\ efficacy was related to self-efficacy for teamwork, horizontal allocentrism, and the extent to which a team \\ member perceived the level of integrating ideas and team tasks to be interdependent.

\section{Disciplines} \\ Education | Social and Behavioral Sciences

\section{Publication Details} \\ Alavi, S. Babak. \& McCormick, J. (2018). Why do I think my team is capable? A study of some antecedents \\ of team members' personal collective efficacy beliefs. Educational Psychology: an international journal of \\ experimental educational psychology, 38 (9), 1147-1162.
}




\title{
Why do I think my team is capable? \\ A study of some antecedents of team members' individual collective efficacy beliefs
}

\begin{abstract}
Although several studies have investigated collective efficacy and its antecedents, few have been conducted about antecedents and consequences of team members' individual beliefs of their team's collective efficacy (personal collective efficacy). We argue that this individual belief is a motivational factor for teamwork along with self-efficacy for teamwork. This study investigated relationships between team members' individual assessments of collective efficacy, their self-efficacy for teamwork, collective orientations, and perceptions of self in relation to other team members. In addition, relationships between personal collective efficacy and team members' perceptions of team activities namely evaluating and integrating were explored. Multilevel analysis was employed in order to account for team level variation when testing individual level relationships. Eighty-six university student teams involved in performing interdependent academic tasks were followed throughout a two-stage longitudinal study. Results showed that personal collective efficacy varied significantly at the individual level, and the relatively small variance at the team level was significant. We found personal collective efficacy was related to self-efficacy for teamwork and horizontal allocentrism. In addition, personal collective efficacy was related to the extent to which a team member perceived the level of integrating ideas and team tasks to be interdependent.
\end{abstract}

\section{KEYWORDS}

personal collective efficacy, shared collective efficacy, self-efficacy for teamwork, collective orientation, collective cognition, multilevel analysis.

\section{INTRODUCTION}

Many researchers (e.g., Earley, 1999; Goddard \& Goddard, 2001; Goddard, 2000, 2002; Gully, Incalcaterra, Joshi, \& Beaubien, 2002; Klassen, Usher, \& Bong, 2010; Liu, J., Chen, \& Tao, 2014) have found collective efficacy positively predicts group effectiveness. According to Bandura, “collective efficacy is defined as a group's shared belief in its conjoint capabilities to organize and execute the course of action required to produce given levels of attainments" 
(Bandura, 1997, 477). Notwithstanding, it has been argued that an individual's belief of collective efficacy is also worthy of consideration (Goddard \& Goddard, 2001; Vera, Le Blanc, Taris \& Salanova, 2014; Watson, Chemers, \& Preiser, 2001; Zellars, Hochwarter, Perrewe, Miles, \& Kiewitz, 2001). From this perspective, personal collective efficacy refers to an individual's (e.g., a team member's) belief about his or her group's capabilities to organize and execute the course of action required to produce given levels of performance. Thus, collective efficacy can be conceptualized as both a shared and a personal belief (Watson et al. 2001). Some researchers have also considered collective efficacy as a characteristic of an organization (e.g., Alavi, 2005; Bohn, 2010; Capone \& Petrillo, 2015).

We propose that understanding the role of personal collective efficacy can be critical in educational settings, as students need to consider their learning teams capable of performing their tasks in order to engage in team activities. It is proposed that a team member having high personal collective efficacy can increase the perceived likelihood of success, and therefore, it can be considered a motivational belief in team contexts at the individual level. Despite the importance of this phenomenon, few studies have been conducted to understand personal collective efficacy as well as the main antecedents of this belief.

The study reported here investigated some antecedents of personal collective efficacy. Considering the role of personal collective efficacy in motivating students for team learning, we argue that understanding the antecedents of personal collective efficacy can be critical in educational settings because universities and instructors may need some policies or procedures for enhancing students' motives for teamwork, and members of learning teams may also need some capabilities or orientations that can foster their learning processes during teamwork. Although some antecedents of collective efficacy as a shared belief have been investigated in some studies (e.g., Alavi \& McCormick, 2008; Gibson \& Earley, 2007; Huh \& Reigeluth, 
2004; Pescosolido, 2001), to the best of the authors' knowledge, the antecedents of individual collective efficacy have not been studied. This study makes this contribution.

\section{THEORETICAL BACKGROUND AND HYPOTHESES DEVELOPMENT}

\section{Conceptualization and measurement of collective efficacy in studies of teams}

Social cognitive theory proposes three types of agency: personal, proxy, and collective. According to Bandura (1997) "agency refers to acts done intentionally" (p. 3). Although individuals act based on personal agency, they may also perceive themselves to be part of a collective when they rely on each other to achieve their common goals, exercising collective agency. Bandura (1997) argued that people do not live in social isolation and pursue their goals by working collectively with others in many situations. Bandura (1997) also suggested that collective efficacy is rooted in self-efficacy. These beliefs are conceptually different, but inter-related: "In reality, they usually go together because people have to rely, at least to some extent, on others in accomplishing their tasks" (Bandura, 1997, p. 469).

From this perspective, collective efficacy is a shared belief held by the collective, which is essential for collective actions. There is empirical support for the role of collective efficacy in collective actions such as teamwork and team-based learning in work and educational settings (Cannon-Bowers, Salas, \& Sharolyn, 2001; Goddard \& Goddard, 2001; Klimoski \& Mohammed, 1994; Vera et al., 2014). Collective efficacy as a shared belief has been frequently identified as an important predictor of team performance, especially when teams perform highly interdependent tasks (Bandura, 1997; Erez \& Katz, 2002; Gully, et al. 2002).

Although most studies of collective efficacy has considered it as a shared belief, few studies have proposed that individuals' beliefs of the capabilities of the collective may also be important motivationally for individual functioning as part of the team, in terms of effort and commitment toward teamwork (Watson et al., 2001; Zellars et al., 2001; Vera et al., 2014). 
When team members believe their team is highly capable of performing team tasks successfully, they may readily participate effectively in team processes. This suggests that it is worthwhile to investigate some antecedents of this individual level belief although it seems that it is rarely studied.

From a methodological perspective, study of collective efficacy as a personal or shared belief depends on the level of analysis, which "refers to the unit to which the data are assigned for hypothesis testing and analysis" (Gully et al., 2002, p. 820). Two levels of analysis (individual and team) may readily be identified in studies of teams. Bandura (1997) argued that some agreement within a group on the group's capabilities is necessary for studying collective efficacy as a group phenomenon.

\section{Research arguments and hypotheses}

Before providing theoretical arguments and hypotheses, the main constructs of the study are defined. Self-efficacy for teamwork refers to a team member's appraisal of her or his capabilities to perform team tasks and behaviors; In addition, self-efficacy for teamwork in terms of team activities such as idea exchanging and integrating can be a context and task specific belief, consistent with the context of the study. Collective orientation is defined as a team member's set of beliefs about self-interdependence with and self-independence from other team members. In particular, collective orientation is conceptualized in terms of vertical and horizontal idiocentrism and allocentrism. (Alavi \& McCormick, 2004). 'Horizontal idiocentrics' generally believe themselves to be independent from but similar to other team members. 'Vertical idiocentrics' tend to emphasize being different from and better than other team members at performing team tasks. 'Horizontal allocentrics' generally perceive themselves to be interdependent with other team members as well as equal to them. Although 'vertical allocentrics' generally perceive themselves interdependent with other team members, 
they have subordinative perceptions of self to the team. Collective orientation was incorporated into this study, as it has been a critical factor in teamwork in several studies of teams (Alavi \& McCormick, 2004), and is likely to influence how capable his or her team is for jointly performing its tasks. The extent to which individuals perceive themselves interdependent with or independent from other team members at the initial stages of teamwork may influence the extent of their interactions during team processes for completion team tasks. The vertical and horizontal dimensions are arguably important because these may influence team processes, which in turn, may influence collective efficacy. In addition, during team processes and at the final stages of teamwork, team members may attribute collective efficacy beliefs to the extent to which they perceive themselves to be independent or interdependent.

The term 'collective cognition' has been used to explain group processes in terms of group members' ideas and information. Gibson (2001) proposed a collective cognition model, which may sequentially form a group's decisions and actions in a developmental cycle of idea processing. The collective cognition model may explain team members perceiving new information, storing information, identifying the domain of expertise of each group member, negotiating, evaluating ideas, and decision making (Gibson, 2001). Three activities of the model, 'exchanging', 'evaluating', and 'integrating' ideas, have been emphasized in this study. Exchanging ideas refers to a group activity aimed at the discovery and free exchange of members' personal ideas and viewpoints (Gibson, 2001). Evaluating refers to collective, constructive evaluation of team members' ideas and viewpoints (Gibson, 2001). Integrating refers to cooperative discussion in terms of taking into account team members' ideas aimed at integration of multiple views (Gibson, 2001). During these activities, team members may interact with each other's knowledge, skills, attitudes, and beliefs (Gibson, 1999, 2001). Team members' personal and shared mental models may be developed or modified during these processes (Mohammed \& Dumville, 2001). Given that the context of this study was university 
student teams involved in learning activities, we considered this framework to have considerable potential for explaining students exchanging and integrating of their ideas, and their personal collective efficacy for their teams.

Task interdependence refers to the extent to which team tasks require team members to work independently (Pearce \& Gregersen, 1991). Task interdependence may affect personal collective efficacy in terms of influencing the levels of collective cognition activities in teams, which relate to personal collective efficacy. In addition to the importance of task interdependence in team processes as an objective phenomenon, it has also been suggested that team members' perceptions of task interdependence may also influence team processes (Barnett \& McCormick, 2016). In addition, team members' perceptions of task interdependence may vary over time, because of the way they work interdependently may change (Gully, et al., 2002).

Although, various relationships may be identified between the constructs introduced above, only some key relationships with personal collective efficacy were highlighted and hypothesized, considering the main goal of the study.

It has been suggested that collective efficacy is rooted in team members' self-efficacy (Bandura, 1997). A team member may partly attribute the capabilities of his or her team for performing the team's tasks to his or her own personal capabilities in teamwork with other team members because of the interdependent nature of team activities. That is, given the context and task specific nature of self-efficacy- self-efficacy for teamwork in this study- a team member's self-efficacy for teamwork may be considered a justification for the member to believe in the capabilities of the group for performing team tasks. This relationship with the opposite direction may also be proposed. A team member may also partly relate his or her self-efficacy for teamwork to the extent to which the team is perceived to be capable of jointly performing its tasks, because of the interdependency required for performing team tasks. 
Hypothesis 1. Self-efficacy for teamwork will positively be related to personal collective efficacy.

Personal collective efficacy may be related to collective orientation. Theoretical arguments may be developed for the relationships between the four dimensions of collective orientation (Alavi \& McCormick, 2004) and personal collective efficacy. It is likely that when team members generally have higher levels of horizontal allocentrism, they are more likely to perceive their team to be a collective agent (Bandura, 1997) than otherwise. Therefore, horizontal allocentrism supports team processes, which enable team members to perform their tasks interdependently resulting in high collective efficacy. Because team members are likely to perceive the team as a collective, a strong sense of interdependence in the early stages of teamwork may result in high personal collective efficacy. In addition, when team members perceive their team to be capable of performing its tasks during teamwork, they likely perceive themselves interdependent with other team members. Furthermore, having high collective efficacy may also result in a heightened sense of collectivity, which may also increase horizontal allocentrism during teamwork.

Other dimensions of collective orientation may also influence personal collective efficacy. Vertical allocentrism may be similar to horizontal allocentrism in forming a sense of interdependence. However, given the priority of the team to individual preferences in vertical allocentrism, the influence of vertical allocentrism on personal collective efficacy may differ from horizontal allocentrism. Both dimensions of idiocentrism may also negatively influence team processes and collective efficacy given the emphasis on individuality. However, some aspects of collective cognition such as evaluation may require some degree of idiocentrism and independent judgments. Thus, although a positive relationship may be argued for the relationship between horizontal allocentrism and personal collective efficacy, understanding 
the relationships between other dimensions of collective orientation and personal collective efficacy need further exploration. A research question was developed for further analysis:

Research question 1: What are the relationships between four dimensions of collective orientation with personal collective efficacy?

With respect to Gibson's (2001) model, collective cognition activities are arguably necessary for development of effective decisions and actions. Working in a team and developing a comprehensive team report may require team members to frequently exchange, evaluate, and integrate their ideas, especially for highly intellectual tasks. It follows that when team members exchange their ideas openly, constructively evaluate each other's ideas, and effectively integrate their thoughts during team processes to make decisions and perform their tasks, they are likely to perceive their team to be capable of performing its tasks (Gibson, 1999; Gibson \& Earley, 2007). In particular, effective integrating as the basis of decision-making and acting (Gibson, 2001) may greatly influence collective efficacy because a tem member may perceive his or her team to be capable of performing its tasks when team members are perceived to be engaged in integrating ideas and actions required for performing team tasks. In addition, when team members perceive their teams to be capable of performing their tasks, they may put greater effort into teamwork (e.g., because of high probability of achieving goals by exerting effort) than if they perceive collective capabilities to be low.

Hypothesis 2. Perceived collective cognition activities will positively be related to personal collective efficacy.

As mentioned earlier, task interdependence may be operationalized objectively and subjectively (Barnett \& McCormick, 2016). That is, even when the objective task interdependence is identified at the beginning of teamwork, team members' perceptions of task 
interdependence may change over time dynamically (Gully et al., 2002). Different cues and work patterns may be considered subjective signals for the development of perceived task interdependence. We argue that during teamwork when team members realize that their team tasks are performed interdependently, they may partly consider it as an indication of the capability of their team to jointly succeed in performing team tasks and attaining their collective goals. In addition, when team members perceive their team capable of performing its tasks, which require them to work interdependently, they are more likely to assign their tasks interdependently. This may also result in perceptions of performing team tasks interdependently. Thus, the following hypothesis can be proposed:

Hypothesis 3. Perceived task interdependence will positively be related to personal collective efficacy.

\section{METHODS}

\section{Participants and procedures}

The potential participants of this study were 895 students enrolled in seven courses of Local Planning, Health Promotion, Physics Laboratory Research Projects, Fundamentals of Physics, Physics for Building and Civil Engineering, Physics for Industrial Design, and Health Services Development and Implementation, in a university in Sydney, Australia. These students were required to work interdependently in teams to carry out team assignments or projects during the semester. Students were required to interact intellectually to solve cases in strategic planning of a health system by analyzing internal and external factors, analyzing urban issues and provide solutions to policy makers, and identifying explanations for the results of some experiments in a laboratory. These team tasks can be categorized into "Intellective or problem-solving tasks" (McGrath, 1984; Straus, 1999), which require choosing correct answers, and judgment or decision-making, and reaching consensus on a preferred answer. An 
analysis of group tasks supported the idea that students were required to conduct activities similar to collective cognition activities (e.g., exchanging, evaluating, and integrating ideas).

A two-phase longitudinal design was used because it was expected a measure of personal collective efficacy likely is more available and reliable when team members work in a team for a reasonable period of time. Team members may not develop collective efficacy beliefs if they have insufficient time for team interaction. In addition, self-efficacy for teamwork and collective orientation at the early stages of teamwork were expected to influence collective cognition activities and personal collective efficacy after team members had interacted sufficiently with each other. Therefore, personal collective efficacy was considered in the second stage of the study along with other variables proposed in the hypotheses. In addition, some antecedents introduced in the hypotheses that could exist at the beginning of teamwork were also included in the first stage of the study. Collective orientation was also included in the second phase, because it was expected that personal collective efficacy is formed while team members develop beliefs about their interdependence with, and independence from, each other during teamwork (see Research Question 1).

The first phase was conducted in week two of the semester. The first questionnaire and a consent form were given to each student, and all were requested to participate in the study. The second phase was conducted two weeks before completion of the teamwork exercise (week ten).

\section{Instruments}

The phase one questionnaire consisted of four parts. The first part of the questionnaire requested demographic information, including students' self-reported rating of verbal English proficiency. Students were requested to indicate age, gender, first language, and family's 
ethnic background. Students were also requested to provide their names and the names of their teammates to identify the team composition. Collective orientation and self-efficacy for teamwork items were placed in the second and third parts of the questionnaire, respectively.

The phase two questionnaire consisted of five parts: demographic information, and items for perceived collective cognition, personal collective efficacy, perceived task interdependence, and collective orientation. For the controlling purpose, students were also asked about past teamwork experiences with the same team, the number of meetings during the teamwork exercises, and extent of e-mail use during teamwork.

Twenty-four items were developed for collective orientation after considering items used in some other studies (e.g., Earley, 1993; Eby \& Dobbins, 1997; Triandis \& Gelfand, 1998; Wagner, 1995) with reference to vertical and horizontal dimensions of allocentrism and idiocentrism (Alavi \& McCormick, 2004) in the context of student teams. Some sample items are: "I like to help other group members if they have some problems performing their tasks" for horizontal allocentrism, "It is important to me that I do my job better than other group members." for vertical allocentrism, "My personal identity is very important to me" for horizontal idiocentrism, and "Even when I strongly disagree with group members, I should avoid an argument" for vertical idiocentrism.

Self-efficacy for teamwork was measured in a way consistent with Bandura's recommendation (Bandura, 2001, 1997). Self-efficacy for teamwork items were developed with regard to common team tasks and behaviors expected in the team activities. Twenty one items such as 'I can encourage other group members to explain their viewpoints' and 'I can give feedback to other group members about my understanding of their ideas' were developed to measure self-efficacy for teamwork. An 11-point scale ranging from $0 \%$ (not at all confident) to $100 \%$ (completely confident) was used (Bandura, 2001). 
Team members' perceptions of exchanging, evaluating, and integrating ideas in their teams were measured using statements, which operationalized collective cognition activities (Gibson, 2001). Twenty four items were developed to measure collective cognition activities during teamwork, e.g., 'Group members allow each other to explain their ideas openly', 'Group members constructively identified the weaknesses of each other's ideas', and 'We took different perspectives into account before making decisions'. A seven-point scale ranging from 0 "never" to 6 "always" was used.

Considering Bandura's (1997) approach to measuring collective efficacy, eleven items were developed with respect to different aspects of team tasks such as 'We can organize the group's activities to complete the set tasks in the available time' and 'The group can effectively generate sufficient ideas to answer a question'. An 11-point scale ranging from $0 \%$ (Not at all confident) to $100 \%$ (Completely confident) was used.

Perceived task interdependence was measured based on items developed by Pearce and Gregersen (1991) such as 'My tasks required me to consult with other group members fairly frequently'. A seven-point scale ranging from 1 (Strongly disagree) to 7 (Strongly agree) was used to measure this construct.

\section{ANALYSIS AND DISCUSSIONS}

\section{Demographic information and control variables}

Two hundred and seventy students participated in both phases of this study (response rate $30 \%$ ), and formed the effective sample. Fifty seven percent were male, and $42.3 \%$ were female. The mean age was 21 years with a standard deviation of 4.86 . Seventy five percent of the participants were at the undergraduate level and $25 \%$ at the postgraduate level. English was 
the first language of $31.9 \%$ of participants. The most common ethnic backgrounds were Chinese (30.8\%) and Australian (16.1\%).

Although individualism and collectivism were not directly measured in this study because of practical limitations, the 'individualistic background' and 'collectivistic background' terms were used to categorize students' ethnic backgrounds in order to identify the cultural similarity of teams only as a control variable. The family's ethnic backgrounds of students were used for this categorization. From this perspective, $63 \%$ of participants had collectivistic and $33 \%$ had individualistic backgrounds. Cultural proximity of a team was scored as ' 1 ' when all members had a similar cultural background in terms of individualism and collectivism, and ' 0 ' for when at least one member had a different cultural background from other members. Language proximity, another contextual factor, was scored ' 1 ' when all members had the same first language, and ' 0 ' when at least one member had a different first language from the other members. Gender proximity was scored ' 1 ' when all members had the same gender, and ' 0 ' when at least one member had a different gender from other members. 'Physical proximity' was operationalized in terms of four team-level variables, 'using e-mail in team communication', 'number of convened meetings before phase one' $(\mathrm{M}=1.06 ; \mathrm{SD}=.52)$, 'number of convened meetings before phase two' $(\mathrm{M}=4.68 ; \mathrm{SD}=1.98)$, and 'number of times working with the same team in other courses' $(\mathrm{M}=.61 ; \mathrm{SD}=1.43)$. Using e-mail in team communication $(\mathrm{M}=3.08$; $\mathrm{SD}=2.22$ ) was measured on a 9 point scale ranging from 0 "No use" to 8 "Use for all communication".

\section{Measurement models}

Exploratory factor analysis was used initially in the development of the measurement models at the individual level. Principal axis factoring and direct oblimin rotation revealed a four-factor solution for collective orientation in phase one with no substantial cross-loadings. 
The eigenvalues were $3.54,3.13,1.8$, and 1.13 , respectively, and the factors explained $18.6 \%$, $16.5 \%, 9.5 \%$, and $5.9 \%$ of the total variance, respectively. Cronbach alphas were $0.73,0.76$, 0.72, and 0.52 respectively. Factors were named vertical idiocentrism, horizontal allocentrism, horizontal idiocentrism, and avoiding arguments. Only two items ("Even when I strongly disagree with group members" and "I should avoid an argument") formed avoiding arguments. This suggested that vertical allocentrism may not be as meaningful as other dimensions of collective orientation in this student team context. The final measurement model of collective orientation was confirmed with phase two data, and had acceptable fit statistics (see Table 1). Principal axis factoring also revealed a one-factor solution for self-efficacy for teamwork (Phase one), personal collective efficacy (Phase two), and perceived task interdependence (Phase two) The eigenvalues were 11.30, 6.93, and 2.90, respectively, and the factors explained $53.8 \%, 63.0 \%$, and $57.9 \%$ of the total variances of the variables, respectively. Cronbach's alphas were $0.95,0.95$, and $82 \%$ respectively. The measurement model of self-efficacy for teamwork and perceived task interdependence after some modifications had acceptable measures of fit (see Table 1). The measurement model of personal collective efficacy was confirmed with no modifications (see Table 1). Principal axis factoring with oblimin rotation method revealed two factors for collective cognition activities. The eigenvalues were 7.58 and 1.47, respectively, and the factors explained $47.4 \%$ and $9.2 \%$ of the total variation. Cronbach alphas were 0.91 and $0.82 \%$, respectively. Factors were labeled integrating and evaluating. After conducting exploratory factor analysis described above, confirmatory factor analysis was also conducted for further confidence of the validity and reliability of our measurement models considering the above factors. Table 1 shows that the measurement models had acceptable measures of fit after some modifications. 
Table 1

about here

\section{Multilevel regression models}

Multilevel analysis enables researchers to consider individual level variance as well as differences between groups (Snijders \& Bosker, 1999). Hence, multilevel analysis can enable researchers to study collective efficacy at the individual.

The variance-decomposition models of the fourteen main variables were estimated to identify statistically significant variance at the team level. Table 2 shows individual, team, and total variance of variables. Kenny and colleagues (2002) recommended using the RIGLS estimation method, which minimizes estimation bias when analyzing small groups. Only six variables were found to have statistically significant variance at the team level. These were personal collective efficacy, perceived integrating, horizontal idiocentrism in phase two, vertical idiocentrism in phase two, horizontal allocentrism in phase one, self-efficacy for teamwork, and perceived verbal English proficiency. Although these significant variations were identified, it was important to examine variance after including courses in the multilevel regression models. The models indicated statistically significant variance at the team level for personal collective efficacy, perceived integrating, horizontal idiocentrism in phase two, and perceived verbal English proficiency although, most variance was at the individual level. It is possible that because of the interdependent nature of tasks and the time period that students had during teamwork, they were able to develop shared perceptions of their collective cognition activities as well as shared beliefs of their capabilities. The intraclass correlations were $21.6 \%$, $18.4 \%, 18.2 \%$, and $30.1 \%$, respectively. In addition, $r_{W G(J)}$ for variables (James et al., 1984, 1993) were between 0.8 to 0.9 . 
Table 2

about here

Figure 1 shows the caterpillar plot of collective efficacy residuals at the team level after controlling for courses. This diagram shows the residuals of three teams are significantly below zero, and the residuals of five teams are significantly above zero. Although variance at the team level is statistically significant, most variation was at the individual level (78.4\%). Accounting for team level variations, the relationships between variables at the individual level can be identified without misestimation (Goldstein, 1995).

Figure 1

about here

Table 3 shows a multilevel regression model with personal collective efficacy as the dependent variable. Variables were entered into the model based on the order of classes (G1 to G6 dummy variables for controlling courses), personal and team characteristics as the inputs of teamwork, phase one variables, and phase two variables. Self-efficacy for teamwork was a statistically significant predictor of personal collective efficacy (supporting hypothesis 1). Horizontal allocentrism in phase two was also a significant predictor of personal collective efficacy in phase 2 (in relation to Research Question 1). Another significant predictor of personal collective efficacy (phase 2) was avoiding arguments in phase two. That is, students' perceptions of their team's capabilities were related to their beliefs that they should avoid 
arguments when other team members were in agreement (in relation to Research Question 1). Perceived task interdependence was also a significant predictor of personal collective efficacy (supporting hypothesis 3). The strongest relationship in the model (see Table 3) is between personal collective efficacy and perceived integrating. This result partly supports hypothesis 2 , given that perceived evaluating was not identified as a significant predictor of personal collective efficacy. It may be argued that integrating ideas during teamwork emphasized the collective nature of the team, likely affecting the development of collective efficacy.

Table 3

about here

\section{CONCLUSIONS}

The results of this study support the idea of the importance of personal collective efficacy beliefs for team members' involvement in performing team tasks with other team members. The main contribution of this study is that to the best knowledge of the authors, this is the first study that has identified some antecedents for personal collective efficacy in university student team contexts. This can help researchers and practitioners better understand how this motivational belief can be formed. The relationship identified between perceived task interdependence and personal collective efficacy arguably is important for educational purposes, given that many educational learning activities are team-based and all team members are typically required to work interdependently to perform their team tasks. It is proposed to design team tasks in a way that students are required to work interdependently rather than working independently. Other findings suggest that integrating ideas is important for intellectual team activities and students' motives for participation in teamwork. Considering the 
cross sectional design of this study, we also propose that high personal collective efficacy may improve a team member's involvement in teamwork and interactions with other team members in order to integrate team ideas and actions. Although this study had no intervention during teamwork, teachers may be able to help student teams increase their collective efficacy during teamwork, which may in turn motivate students for increasing their engagement in team activities. In addition, self-efficacy for teamwork in the beginning of teamwork was identified as an important factor in forming personal collective efficacy. This is important to realize that students' self-efficacy for teamwork can be an asset for successful teamwork in educational settings. The success of teamwork may be related to team members' self-efficacy for teamwork formed by past successful teamwork experiences. This can be an important objective for educational systems to provide programs for increasing students' self-efficacy for teamwork that can foster other teamwork activities during their university teamwork activities. This study also suggests that student teams may be more productive when students have high self-efficacy for teamwork. Considering the relationship between horizontal allocentrism and personal collective efficacy, it is suggested that teachers may be able to increase students' interdependence orientation during teamwork that can improve their team capabilities to perform their tasks.

This study had some key limitations that should be acknowledged. First, although personal collective efficacy is likely to be related to numerous cognitive, behavioral, and contextual factors, this study included only a limited number of factors. Second, self-efficacy for group work initially planned to be incorporated in both phases, but was only included in Phase 1 because of the practical limitation of the number of variables in Phase 2. The results of this study propose some directions for further investigations. Although task interdependence was related to personal collective efficacy, further research is needed to explore different types of task designs that may be helpful for increasing the chance of high personal collective 
efficacy essential for encouraging team members to participate in team activities. In addition, it may be worthwhile to identify practices that may be used to increase horizontal allocentrism which may in turn improve personal collective efficacy. Furthermore, more inquiries may be helpful to identify team practices that can enhance integrating ideas in such team activities.

\section{REFERENCES}

Alavi, S. B. (2005, September). A multilevel approach to studying collective efficacy in organizational change. Paper presented at Tehran International Management Conference, Tehran, Iran.

Alavi, S. B., \& McCormick, J. (2004). Theoretical and measurement issues for studies of collective orientation in team contexts. Small Group Research, 35, 111-127.

Alavi, S. B., \& McCormick, J. (2008). The roles of perceived task interdependence and group members' interdependence in the development of collective efficacy in university student group contexts. British Journal of Educational Psychology, 78, 375-393.

Bandura, A. (1997). Self-efficacy: the exercise of control. New York: W. H. Freeman and Company.

Bandura, A. (2001). Guide for constructing self-efficacy scales (Revised March, 2001). (HTML Paper: http://www.emory.edu/EDUCATION/mfp/effpage.html).

Barnett, K., \& McCormick, J. (2016). Perceptions of Task Interdependence and Functional Leadership in Schools. Small Group Research, 47, 279-302.

Bohn, J. G. (2010). Development and exploratory validation of an organizational efficacy scale. Human Resource Development Quarterly, 21, 227-251.

Cannon-Bowers. J. A., \& Salas. E., Sharolyn. C. (2001). Reflection on shared cognition. Journal of Organizational Behavior, 22, 195-202. 
Capone, V., \& Petrillo, G. (2015). Organizational efficacy, job satisfaction and well-being: The Italian adaptation and validation of Bohn organizational efficacy scale. Journal of Management Development, 34, 374-394.

Earley, P. C. (1999). Playing follow the leader: Status-determining traits in relation to collective efficacy across cultures. Organizational Behavior and Human Decision Processes, 80, 192-212.

Eby, L. T., \& Dobbins, G. H. (1997). Collectivistic orientation in teams: An individual and group-level analysis. Journal of Organizational Behavior, 18, 275-295.

Erez, M., \& Katz, T. (2002). Structural and cultural effects on the emergence of collective-efficacy, and on the collective-efficacy - performance relationships. Paper presented at the Academy of Management Meeting, Sydney, 2002.

Gibson, C. B. (1999). Do they do what they believe they can? Group efficacy and group effectiveness across tasks and cultures. Academy of Management Journal, 42, 138-152.

Gibson, C. B. (2001). From knowledge accumulation to accommodation: cycles of collective cognition in work groups. Journal of Organizational Behaviour, 22, 121-134.

Gibson, C. B., \& Earley, P. C. (2007). Collective Cognition in Action: Accumulation, Interaction, Examination, and Accommodation in the Development and Operation of Group Efficacy Beliefs in the Workplace. Academy of Management Review, 32, 438-458.

Goddard (2000). Collective efficacy and student achievement. Paper presented at the annual meeting of the American Educational Research Association, New Orleans.

Goddard, R. G. and Goddard, Y. L. (2001). A multilevel analysis of the relationship between teacher and collective efficacy in urban schools. Teaching and Teacher Education, 17, 807-818. 
Goddard, R. G. (2002). A theoretical and empirical analysis of the measurement of collective efficacy: The development of a short form. Educational and Psychological Measurement, $62,97-110$.

Goldstein, H. (1995). Multilevel statistical models. London: Edward Arnold.

Gudykunst, W. B., Matsumoto, Y., Ting-Toomey, S., Nishida, T., Kim, K. S., \&Heyman, S. (1996). The influence of cultural individualism-collectivism, self-construals, and individual values on communication styles across cultures. Human Communication Research, 22, $510-543$

Gully, S. M., Incalcaterra, K. A., Joshi, A., \& Beaubien, J. M. (2002). A meta-analysis of team-efficacy, potency, and performance: Interdependence and level of analysis as moderators of observed relationships. Journal of Applied Psychology, 87, 819-832.

Hofstede, G. (2001). Culture's consequences. California: Sage Publications.

Huh, Y., Reigeluth, C. M., \& Lee, D. (2014). Collective Efficacy and its Relationship with Leadership in a Computer-mediated Project-based Group Work. Contemporary Educational Technology, 5. 1-21.

James, L. R., Demaree, R. G., \& Wolf, G. (1984). Estimating within-group interrater reliability with and without response bias. Journal of Applied Psychology, 69, 85-98.

James, L. R., Demaree, R. G., \& Wolf, G. (1993). $r_{w g}$ : An assessment of within-group interrater agreement. Journal of Applied Psychology, 78, 306-309.

Klassen, R. M., Usher, E. L., \& Bong, M. (2010). Teachers' collective efficacy, job satisfaction, and job stress in cross-cultural context. The Journal of Experimental Education, 78, 464-486.

Kenny, D. A., Mannetty, L., Pierro, A., Livi, S., \& Kashy, D. A. (2002). The statistical analysis of data from small groups. Journal of Personality and Social Psychology, 83, 126-137. 
Klimoski. R., \& Mohammed. S. (1994). Team mental model: Construct or metaphor?. Journal of Management, 20, 403-437.

Liu, J., Chen, J., \& Tao, Y. (2014). Innovation Performance in New Product Development Teams in China's Technology Ventures: The Role of Behavioral Integration Dimensions and Collective Efficacy. Journal of Product Innovation Management. DOI: 10.1111/jpim.12177.

McGrath, J. E. (1984). Groups: Interaction and performance. Englewood Cliffs, NJ: Prentice Hall.

Mohammed, S., \& Dumville, B. (2001). Team mental models in team knowledge framework: expanding theory and measurement across disciplinary boundaries. Journal of Organizational Behavior, 22, 89-106.

Oetzel, J. G. (2001). Self-construals, communication processes, and group outcomes in homogeneous and heterogeneous groups. Small Group Research, 32, 19-54.

Pearce, J. L. \& Gregersen, H. B. (1991). Task interdependence and extrarole behaviour: A test of the mediating effects of felt responsibility. Journal of Applied Psychology, 76, $838-844$.

Pescosolido, A. (2001). Informal leaders and the development of group efficacy. Small Group Research, 32, 74-93.

Snijders, T, \&Bosker, R. (1999). Multilevel Analysis: An introduction to basic and advanced multilevel modeling. London: Sage.

Straus, S. G. (1999). Testing a Typology of Tasks An Empirical Validation of McGrath's (1984) Group Task Circumplex. Small Group Research, 30, 166-187.

Triandis, H. C., \& Gelfand, M. J. (1998). Converging measurement of horizontal and vertical individualism and collectivism. Journal of Personality and Social Psychology, 74, 118-128. 
Vera, M., Le Blanc, P. M., Taris, T. W., \& Salanova, M. (2014). Patterns of engagement: the relationship between efficacy beliefs and task engagement at the individual versus collective level. Journal of Applied Social Psychology, 44, 133-144.

Wagner, J. A. (1995). Studies of individualism-collectivism: Effects on cooperation in groups. Academy of Management Journal, 38, 152-173.

Watson, C. B., Chemers, M. M., \& Preiser, N. (2001). Collective efficacy: A multilevel analysis. Personality and Social Psychology Bulletin, 27, 1057-1068.

Wong. S., \& Sitkin. S.B. (2000). Shaping collective cognition and behavior through collective learning, Academy of Management Best Paper Proceedings. MOC-BI.

Zellars, K. L., Hochwarter, W. A., Perrewe, P. L., Miles, A. K., \& Kiewitz, C. (2001). Beyond self-efficacy: Interactive effects of role conflict and perceived collective efficacy. Journal of Managerial Issues, 13, 483-499. 